\title{
Erratum zu: Abenteuer Informatik
}

IT zum Anfassen für alle von 9 bis 99 - vom Navi bis Social Media

\section{Erratum zu:}

\section{J. Gallenbacher, Abenteuer Informatik, https://doi.org/10.1007/978-3-662-53965-1}

Die Kapitel 1, 2, 3, 8, 9, 11, 12, 14 und 15 dieses Buches wurden unter einer CC BY-NC-ND 4.0-Lizenz veröffentlicht und der Urheberrechtsinhaber wurde auf „Der/die Autor(en)“ aktualisiert. Das Buch wurde ebenfalls mit dieser Änderung aktualisiert.

Die aktualisierte Version des Buches finden Sie unter https://doi.org/10.1007/978-3-662-53965-1 